\title{
Longitudinal adherence to maternal antiretroviral therapy and infant Nevirapine prophylaxis from 6 weeks to 18 months postpartum amongst a cohort of mothers and infants in South Africa
}

\author{
Anna Larsen ${ }^{1}$, Vuyolwethu Magasana², Thu-Ha Dinh³ , Nobubelo Ngandu², Carl Lombard², Mireille Cheyip', \\ Kassahun Ayalew ${ }^{1}$, Witness Chirinda ${ }^{2}$, Gurpreet Kindra', Debra Jackson ${ }^{4,5}$ and Ameena Goga ${ }^{2,6,7^{*}}$
}

\begin{abstract}
Background: Despite improved policies to prevent mother-to-child HIV transmission (MTCT), adherence to maternal antiretroviral therapy (ART) and infant Nevirapine prophylaxis (NVP) is low in South Africa. We describe ART adherence amongst a cohort of HIV-positive mothers and HIV-exposed but uninfected infants from 6 weeks until 18 months post-delivery and identify risk factors for nonadherence.

Methods: Data were collected in 2012-2014 through a nationally representative survey of PMTCT effectiveness. Mother-infant pairs were enrolled during the infant's first immunization visit at 6 weeks. Mothers and HIV-exposed infants (2811 pairs) were followed to 18 months at 3-month intervals. Mothers who self-reported being on ART at 6 weeks postpartum $(N=1572(55.9 \%))$ and infants on NVP at 6 weeks $(N=2370(84.3 \%))$ were eligible for this analysis and information about their adherence was captured at each interview they attended thereafter. We defined nonadherence within each 3-month interval as self-report of missing $>5 \%$ of daily ART/NVP doses, estimated adherence using a Cox survival curve with Andersen \& Gill setup for recurring events, and identified risk factors for nonadherence with an extended Cox regression model (separately for mothers and infants) in Stata 13. Results are not nationally representative as this is a subgroup analysis of the follow-up cohort.

Results: Amongst mothers on ART at 6 weeks postpartum, cumulative adherence to maternal ART until 18 months was $63.4 \%$. Among infants on NPV at 6 weeks postpartum, adherence to NVP was $74.5 \%$. Risk factors for nonadherence to maternal ART, controlling for other factors, included mother's age (16-24 years vs. $\geq 34$ years, adjusted Hazard Ratio (aHR): 1.9, 95\% Cl: 1.4-2.5), nondisclosure of HIV status to anyone (nondisclosure vs. disclosure: aHR: 1.7, 95\% Cl: 1.3-2.1), and timing of ART initiation (initiated ART after delivery vs. initiated ART before delivery: aHR: 1.6, 95\% Cl: 1.3-2.0). Provincial variation was seen in nonadherence to infant NVP, controlling for other factors.

(Continued on next page)
\end{abstract}

\footnotetext{
* Correspondence: ameena.goga@mrc.ac.za

${ }^{2}$ Health Systems Research Unit, South African Medical Research Council (HSRU, SAMRC), Pretoria, South Africa

${ }^{6}$ Department of Paediatrics, University of Pretoria, Pretoria, South Africa

Full list of author information is available at the end of the article
}

C The Author(s). 2019 Open Access This article is distributed under the terms of the Creative Commons Attribution 4.0 International License (http://creativecommons.org/licenses/by/4.0/), which permits unrestricted use, distribution, and reproduction in any medium, provided you give appropriate credit to the original author(s) and the source, provide a link to the Creative Commons license, and indicate if changes were made. The Creative Commons Public Domain Dedication waiver (http://creativecommons.org/publicdomain/zero/1.0/) applies to the data made available in this article, unless otherwise stated. 


\begin{abstract}
(Continued from previous page)
Conclusion: Maintaining ART adherence until 18 months postpartum remains a crucial challenge, with maternal ART adherence among the six week maternal ART cohort below 65\% and infant NVP adherence among breastfeeding infants in this cohort below 75\%.This is gravely concerning, given the global policy shift to lifelong ART amongst pregnant and lactating women, and the need for extended infant prophylaxis amongst mothers who are not virally suppressed. Our findings suggest that young mothers and mothers who do not disclose their status should be targeted with messages to improve adherence, and that late maternal ART initiation (after delivery) increases the risk of maternal nonadherence.
\end{abstract}

Keywords: HIV-exposed infants, Postnatal care, Missed visits

\section{Introduction}

Since the introduction of triple antiretroviral treatment (ART) and extended infant prophyaxis by national-level programs to prevent mother to child transmission of HIV (PMTCT) each new generation of infants in SubSaharan Africa has been born with lower prevalence of HIV than the last [1, 2]. Highly active antiretroviral treatment (ART) preserves a mother's overall health, reduces her viral load, and reduces risk of MTCT, while Nevirapine (NVP) as infant HIV prophylaxis prevents infection in HIV-exposed infants [3, 4]. Global gains in PMTCT have reduced transmission such that numerous countries imminently face elimination of maternal to child transmission of HIV (eMTCT)- achieving generations born HIV-free [5, 6].

Despite these gains, an estimated 122,000 children under the age of 15 years acquired HIV infections in sub-Saharan Africa in 2015, most of which were due to MTCT [7]. South Africa remains the country with the highest number of people living with HIV (PLHIV) in the world, 6.4 million PLHIV [8], accounting for $18 \%$ of global HIV prevalence [9]. HIV prevalence among women reporting to public health facilities for antenatal care (ANC) is high at $29.7 \%$ in 2013 [10], demonstrating the magnitude of the PMTCT program required to maintain low MTCT in South Africa.

South Africa has aggressively adopted the World Health Organization's (WHO) increasingly rigorous guidelines for PMTCT since introducing a national PMTCT program in 2002 [11, 12]. Impressively, South Africa reduced early MTCT at $4-8$ weeks postpartum from $9 \%$ in 2009 to $2.6 \%$ (95\% CI 2.0-3.2) in 2012-2013 [13].

Under WHO Option A and Option B (adopted in April 2013), all HIV-positive pregnant and breastfeeding women were entitled to ART for life if eligible by a CD4 count less than 350 cells $/ \mathrm{mm}^{3}$. Under Option A, pregnant women with a CD4 count over 350 cells $/ \mathrm{mm}^{3}$ were eligible for ART prophylaxis from 14 weeks gestation until 7 days postpartum. HIV-exposed infants received daily NVP from birth to 7 days after cessation of breastfeeding or through age 4-6 weeks if the mother was not breastfeeding. Under Option B, pregnant women with a CD4 count over 350 cells $/ \mathrm{mm}^{3}$ were eligible for triple ART from 14 weeks gestation through 7 days after cessation of breastfeeding and all HIV-exposed infants were provided daily NVP through age 4-6 weeks regardless of feeding method [14, 15]. In December 2014, South Africa adopted Option $\mathrm{B}+$ entitling all HIV positive pregnant and lactating women ART for life regardless of clinical indicators [16]. With these efforts, more than 91\% of HIV-positive mothers in South Africa received ART or prophylaxis in 2014 [17].

Despite high coverage of the PMTCT program and successful reduction in MTCT, the first HIV-free generation in South Africa will only be possible once factors influencing ongoing MTCT are alleviated. One such factor - nonadherence to ART among mothers and infants from pregnancy to cessation of breastfeeding - poses a particular threat to MTCT rates by reducing viral suppression and enabling transmission [18]. By understanding the magnitude of nonadherence to ART among mothers and infants and the risk factors for nonadherence, we can inform programmatic shifts to reduce nonadherence and MTCT.

Nonadherence is difficult to measure as it often relies on information that is self-reported by a patient. Concerns remain about the validity of self-reported adherence measures due to memory biases which often overestimate adherence [19]. However, several studies substantiate these measures as appropriate for estimating adherence to ART in developing settings $[20,21]$. While there is no gold standard metric [22], ART adherence between 80 and $99 \%$ is critical to maintain viral suppression, reduce risk of developing drug resistance, and reduce risk of MTCT [23]. Much of the literature regarding ART adherence, sets the threshold for adherence as achieving at least $95 \%$ of prescribed daily doses since this is required for optimal health outcomes [24]. The analyses herein utilize self-reported information to assess $95 \%$ adherence to ART among mothers and infants.

We describe longitudinal, self-reported adherence to ART among HIV-positive mothers and to Nevirapine 
among their HIV-exposed infants at 3-month intervals from 6 weeks to 18 months postpartum within a subgroup of the follow-up cohort for PMTCT evaluation. Further, we identify risk factors for nonadherence with the goal of informing improvements to PMTCT programming that support ART adherence among motherinfant pairs.

\section{Methods}

\section{Study design and population}

This study was a secondary analysis of data collected to evaluate the effectiveness of the national programme to prevent HIV transmission from mother to child in South Africa. The evaluation was a nationally-representative cross-sectional survey conducted in 2012/13 (October 2012-May 2013), with infant follow-up until September 2014. Public sector health facilities were sampled using multi-stage, probability proportional to size methodology using three strata per province based on 6 week client immunization load and antenatal HIV prevalence. The study was powered to produce nationally-representative results of MTCT at 6 weeks. More detailed information about the survey is available in previous publications $[11,13]$.

Mother-infant pairs were enrolled into the study during the infant's first postpartum immunization visit at 6 weeks as national coverage for this first postpartum immunization visit is known to be over $60 \%$ in surveyed areas of South Africa [25]. If the infant was deemed HIV exposed but uninfected at the 6 week cross-sectional visit, mother-infant pairs $[N=2811]$ were eligible and consented for a further cohort survey involving threemonthly follow-up, from 3 until 18 months. The primary outcomes of this 3-to-18 month national cohort will be presented in a separate publication.

\section{Data and blood collection}

Trained nurse fieldworkers interviewed mothers or nonmother caregivers at the 6 week immunization visit and follow-up visits conducted at 14 weeks and six, nine, twelve, fifteen, and 18 months postpartum about sociodemographic information, infant health and feeding practices, maternal understanding of MTCT, HIV testing, postnatal care, and maternal and infant PMTCT prophylaxis and treatment. Approximately $375 \mu \mathrm{l}$ of blood per infant was drawn and dropped onto five preprinted circles on Munktell TFN filter paper to determine infants HIV exposure and infection. Visual aids such as pictures of ARV pills and ARV syrup bottles were used to assist mothers in identifying the type of regimen received. A feeding and medication diary was issued to mothers so they could document medication received, and to assist with recall of missed daily doses during interviews. Non-mother caregivers were not asked questions about maternal health and/or HIV testing and treatment.

\section{Data analysis}

Two analyses were conducted: Maternal ART adherence (ART analysis) amongst mothers eligible for analysis and infant nevirapine (NVP) adherence (NVP analysis) amongst HIV-exposed infants eligible for analysis. Mothers were eligible for inclusion in the ART analysis if they were included in the follow-up cohort of 2811 mother-infant pairs and indicated that they were on ART at 6 weeks post-delivery $(N=1572)$. At each follow-up interval thereafter at 14 weeks, 6, 9, 12, 15, and 18 months postpartum, information about ART adherence was included in the analysis for mothers (not other caregivers) who attended that particular interview and were still taking ART.

Infants were eligible for inclusion in the NVP analysis if they were HIV-exposed, included in the follow-up cohort of 2811 mother-infant pairs and were reported to be on infant NVP at the six week visit, $(N=2370)$. Thereafter, information about NVP adherence was included in the analysis for breastfeeding infants who attended that particular interview and were still on NVP. Mothers and infants who were removed from ART or NVP based on national guidelines were not further analyzed for adherence in this analysis.

Nonadherence to ART among mothers and NVP among infants was defined as reporting taking less than 95\% of daily doses within each three month follow-up interval. For mothers and infants, this was operationalized in two scenarios where some mothers/infants were deemed non-adherent because they had failed to take ART/NVP for more than $5 \%$ of the daily doses in that interval, while others were non-adherent because they had ceased taking ART/NVP within the interval without professional advice. We assumed that medical advice to stop NVP was provided in compliance with national guidelines (therefore indicating adherence). We assumed other reasons for stopping NVP were not in compliance guidelines (therefore indicating nonadherence).

For mothers or infants who reported missing more than $5 \%$ of daily doses, failure date was calculated as the midpoint of the interview interval. For infants who stopped taking NVP during an interval, their age in weeks at NVP cessation was used to calculate date of failure.

Mothers were excluded from the adherence analysis at a particular time point if they had missed an interview during the interval of interest or a non-mother caregiver had responded to the interview, thus information about the mother's adherence was not provided. Infants were no longer included in the analysis if breastfeeding had been stopped in the prior interval, thus removing the 
threat of transmission and the need for NVP per PMTCT guidelines.

We performed frequency analyses to describe characteristics of the mothers and infants and their care. To describe probability of ART or NVP adherence from 6 weeks to 18 months postpartum we plotted extended Cox model survival curves using the stcox and stcurve commands in Stata [26, 27] after preparing the data for Andersen-Gill time-to-event analysis for recurring events $[28,29]$. The Andersen-Gill model is a counting process allowing assessment of multiple nonadherence events across follow-up intervals instead of censoring on the first instance of nonadherence [28, 30, 31].

We fitted multivariable Andersen-Gill extended Cox models to determine risk factors for ART nonadherence among mothers and infants separately. Andersen-Gill models generalize the Cox proportional hazards model, accommodating the non-proportionality of the effect of covariates in the case of recurrent failure events [31]. The resulting coefficients are a measure of all-cause effects across multiple recurrent events as demonstrated in other studies describing risk factors associated with recurring health events [32-35].

Covariates of interest from the information collected at 6 weeks were identified a priori. We used the forward stepwise function to fit the models from these covariates, setting the significance level for addition to the model at $15 \%$ and removal from the model at $20 \%$ [30]. The proportional hazards assumption was upheld for both models which we assessed by running a model that included time-varying covariates. All analyses were performed in STATA 13.1. Because this is a subgroup analysis of the cohort of mothers followed up by the study, the results are not nationally representative. Therefore, results are not adjusted for the study design, non-response and not weighted for live-births.

\section{Ethical consideration}

The protocol was reviewed according to the Centers for Disease Control and Prevention (CDC) human research protection procedures and was determined to be research, but CDC was not engaged. The protocol was also reviewed by the institutional review board of the Medical Research Council of South Africa. Mothers and caregivers provided written informed consent prior to the onset of the interview and assent for infants to undergo blood collection.

\section{Results}

\section{Characteristics of study population}

The majority of the mothers in the study population were between 25 and 34 years old (ART analysis: 59.2\%, NVP analysis: $56.3 \%$ ). Three quarters of the mothers in both samples were educated up to grade 8-12. Most mothers were single (ART analysis: $70.8 \%$, NVP analysis: 73.9\%) (Table 1).

At the six week interview, most mothers reported a main source of income other than their own employment such as a child support grant, disability grant, a partner or husband's support, or another family member's support (ART analysis: 77.9\%, NVP analysis: $80.6 \%)$. Over a third of infants $(37.3 \%)$ were breastfed between birth and 6 weeks. Less than half of the mothers had planned pregnancies (ART analysis: 40.3\%, NVP analysis: $37.1 \%)$.

\section{Adherence to antiretroviral treatment among mothers and infants}

Cumulative probability of adherence to ART until 18 months postpartum was $63.4 \%$ among mothers included in the ART analysis (95\% confidence interval (CI): 60.766.0 ) and $74.5 \%$ among infants included in the NVP analysis (95\% CI: 70.2-81.9) (Fig. 1, Table 2). From 6 weeks to 14 weeks postpartum, adherence to NVP was $96.4 \%$ among infants (95\% CI: 94.3-97.8). From 6 weeks to 14 weeks postpartum, ART adherence was lower amongst mothers at $85.0 \%$ (95\% CI: 82.8-87.0). Cumulative infant NVP adherence was consistently higher than mother ART adherence over the 6 weeks to 18 months postpartum period.

Among both mothers and infants, a higher proportion of nonadherence events were due to stopping treatment not according to national guidelines (range: ART analysis: $73.9-88.4 \%$, NVP analysis: $58.3-100 \%$ ) rather than missing at least $5 \%$ of daily doses (range: ART analysis: 15.2-26.2\%, NVP analysis: 0-41.7\%) (Table 2).

\section{Risk factors of nonadherence to ART among mothers}

Maternal age influenced ART adherence from 6 weeks to 18 months postpartum with adolescents and young women (aged 16-24 years) having a higher hazard of nonadherence events during that period than women over 34 (age 16-24, adjusted Hazard Ratio (aHR): 1.9, 95\% CI 1.4-2.5).

Failing to disclose one's HIV positive status to anyone at baseline was a risk factor for nonadherence (aHR: 1.7, 95\% CI: 1.3-2.1). Not knowing one's CD4 result also increased risk of nonadherence among mothers. Compared to mothers with a known CD4 result, those who had a CD4 test done but results were not received (aHR: 1.3, 95\% CI: 1.1-1.6) or it was not known if CD4 test was done (aHR: 2.1, 95\% CI: 1.4-3.2) were at higher risk for nonadherence.

Mothers who initiated ART after delivery were at higher risk for nonadherence (aHR: 1.6, 95\% CI: 1.3-2.0) than those who initiated ART before delivery. Mothers who delivered their infants outside of health facilities had almost double the hazard of nonadherence than 
Table 1 Characteristics of mothers ( $N=1572)$ on ART at 6 weeks postpartum and infants $(N=2370)$ on NVP at 6 weeks postpartum among a cohort in South Africa in 2012-2014

\begin{tabular}{|c|c|c|}
\hline \multirow[t]{2}{*}{ Characteristics } & $\begin{array}{l}\text { Mothers on ART at } 6 \text { weeks } \\
N=1572\end{array}$ & $\begin{array}{l}\text { Infants on NVP at } 6 \text { weeks } \\
N=2370\end{array}$ \\
\hline & N (\%) & N (\%) \\
\hline \multicolumn{3}{|c|}{ MATERNAL CHARACTERISTICS } \\
\hline \multicolumn{3}{|l|}{ Maternal age } \\
\hline $16-24$ years & $298(19.0)$ & $619(26.1)$ \\
\hline $25-34$ years & $931(59.2)$ & $1334(56.3)$ \\
\hline $35+$ years & $343(21.8)$ & $417(17.6)$ \\
\hline \multicolumn{3}{|l|}{ Education of mother } \\
\hline Grades 1-7 & $297(18.9)$ & $410(17.3)$ \\
\hline Grades 8-12 & $1196(76.1)$ & $1827(77.1)$ \\
\hline Tertiary & $53(3.4)$ & $94(4.0)$ \\
\hline None/DK/NA & $26(1.6)$ & $39(1.6)$ \\
\hline \multicolumn{3}{|l|}{ Marital status } \\
\hline Single & $1113(70.8)$ & $1751(73.9)$ \\
\hline Married & $295(18.8)$ & $395(16.7)$ \\
\hline Co-habiting & $151(9.6)$ & $207(8.7)$ \\
\hline Widowed & $10(0.6)$ & $13(0.6)$ \\
\hline Divorced/separated & $3(0.2)$ & $4(0.2)$ \\
\hline \multicolumn{3}{|l|}{ Province } \\
\hline Northern Cape & $60(3.8)$ & $76(3.2)$ \\
\hline Limpopo & $148(9.4)$ & $233(9.8)$ \\
\hline Eastern Cape & $143(9.1)$ & $206(8.7)$ \\
\hline Free State & $222(14.1)$ & $301(12.7)$ \\
\hline Gauteng & $312(19.9)$ & $471(19.9)$ \\
\hline KwaZulu Natal & $252(16.0)$ & $407(17.2)$ \\
\hline Mpumalanga & $151(9.6)$ & $266(11.2)$ \\
\hline North West & $139(8.9)$ & $201(8.5)$ \\
\hline Western Cape & $145(9.2)$ & $209(8.8)$ \\
\hline \multicolumn{3}{|c|}{ Primary source of income } \\
\hline Other $^{a}$ & $1225(77.9)$ & $1910(80.6)$ \\
\hline Own employment & $347(22.1)$ & $460(19.4)$ \\
\hline \multicolumn{3}{|l|}{ Parity } \\
\hline One child & $323(20.6)$ & $562(23.7)$ \\
\hline 2-3 children & $983(62.5)$ & $1453(61.3)$ \\
\hline $4+$ children & $266(16.9)$ & $355(15.0)$ \\
\hline \multicolumn{3}{|l|}{ Transport to clinic } \\
\hline Walk & $892(56.7)$ & $1309(55.2)$ \\
\hline Taxi/Bus/Train & $603(38.4)$ & $956(40.3)$ \\
\hline Own vehicle & $68(4.3)$ & $89(3.8)$ \\
\hline Other & $9(0.6)$ & $16(0.7)$ \\
\hline \multicolumn{3}{|c|}{ Time to reach clinic (minutes) } \\
\hline $0-30 \mathrm{~min}$ & $1280(81.4)$ & $1919(81.0)$ \\
\hline$>30 \mathrm{~min}$ & $292(18.6)$ & $451(19.0)$ \\
\hline
\end{tabular}


Table 1 Characteristics of mothers $(N=1572)$ on ART at 6 weeks postpartum and infants $(N=2370)$ on NVP at 6 weeks postpartum among a cohort in South Africa in 2012-2014 (Continued)

\begin{tabular}{|c|c|c|}
\hline \multirow[t]{2}{*}{ Characteristics } & $\begin{array}{l}\text { Mothers on ART at } 6 \text { weeks } \\
N=1572\end{array}$ & $\begin{array}{l}\text { Infants on NVP at } 6 \text { weeks } \\
N=2370\end{array}$ \\
\hline & $N(\%)$ & N (\%) \\
\hline \multicolumn{3}{|l|}{ PREGNANCY AND CONTINUUM OF CARE } \\
\hline \multicolumn{3}{|l|}{ Planned pregnancy } \\
\hline No & $936(59.5)$ & $1491(62.9)$ \\
\hline Yes & $633(40.3)$ & $879(37.1)$ \\
\hline DK/NA & $3(0.2)$ & $0(0.0)$ \\
\hline \multicolumn{3}{|l|}{ Timeliness of first ANC visit } \\
\hline$>12$ weeks & $1030(65.5)$ & $1589(67.1)$ \\
\hline$\leq 12$ weeks & $542(34.5)$ & $781(32.9)$ \\
\hline \multicolumn{3}{|l|}{ ANC Visits } \\
\hline$<4$ visits & $156(9.9)$ & $286(12.1)$ \\
\hline $4+$ visits & $1416(90.1)$ & $2084(87.9)$ \\
\hline \multicolumn{3}{|l|}{ Delivery care location } \\
\hline Hospital & $1246(79.3)$ & $1830(77.2)$ \\
\hline Clinic & $283(18.0)$ & $456(19.3)$ \\
\hline Home/other & $43(2.7)$ & $84(3.5)$ \\
\hline \multicolumn{3}{|l|}{ PNC Visits } \\
\hline$<3$ visits & $1269(80.7)$ & $1885(79.5)$ \\
\hline $3+$ visits & $303(19.3)$ & $485(20.5)$ \\
\hline \multicolumn{3}{|l|}{ Ever breastfed infant in first 6 weeks } \\
\hline No & $1005(63.9)$ & $1485(62.7)$ \\
\hline Yes & $567(36.1)$ & $885(37.3)$ \\
\hline \multicolumn{3}{|l|}{ HIV TESTING AND TREATMENT FACTORS } \\
\hline \multicolumn{3}{|c|}{ HIV status disclosed to family and/or friends } \\
\hline No & $177(11.3)$ & $400(16.9)$ \\
\hline Yes & $1395(88.7)$ & $1970(83.1)$ \\
\hline \multicolumn{3}{|l|}{ Aware of CD4 cell count } \\
\hline CD4 test done and result received & $1037(65.9)$ & $1519(64.1)$ \\
\hline CD4 test not done & $49(3.1)$ & $119(5.0)$ \\
\hline CD4 test done, result not received & $441(28.1)$ & $668(28.2)$ \\
\hline Do not know if had CD4 test & $45(2.9)$ & $64(2.7)$ \\
\hline \multicolumn{3}{|l|}{ Ever heard of PMTCT } \\
\hline No & $192(12.2)$ & $288(12.2)$ \\
\hline Yes & $1380(87.8)$ & $2082(87.8)$ \\
\hline \multicolumn{3}{|l|}{ Initiated ART after delivery } \\
\hline No & $599(38.1)$ & $691(29.1)$ \\
\hline Yes & $783(49.8)$ & $1457(61.5)$ \\
\hline Don't know/Chose not to answer & $190(12.1)$ & $222(9.4)$ \\
\hline
\end{tabular}

${ }^{a}$ Other primary sources of income include: Child support grant, disability grant, partner/husband/ex-husband, other family member

those who delivered at a facility (aHR: $1.9,95 \%$ CI: $1.2-$ 3.0), however only 43 mothers delivered outside of the facility.
Parity and whether the pregnancy was planned were included in the model but were not significantly associated with nonadherence. 


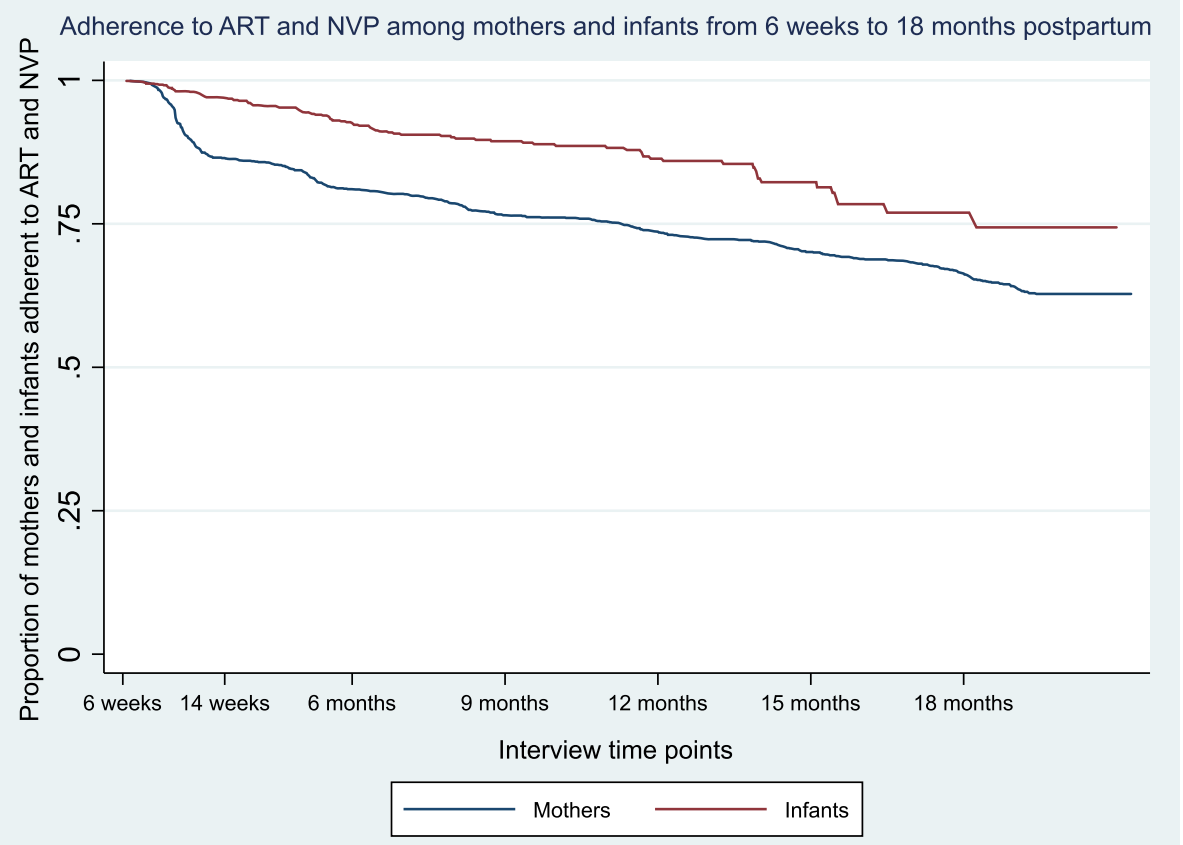

Fig. 1 Adherence to ART among a cohort of mothers $(N=1572)$ and NVP among a cohort of infants $(N=2370)$ at 6 weeks, in South Africa and followed-up at 3-month intervals from 6 weeks to 18 months postpartum in 2012-2014 (unweighted)

\section{Risk factors of nonadherence to Nevirapine among infants}

Provincial variation in NVP nonadherence in the 6 week to 18 month postpartum period was seen in the infant population with those in Northern Cape, North West, Western Cape, and Eastern Cape experiencing the highest hazard of nonadherence compared to those in Free State (Northern Cape, aHR: 5.3, 95\% CI: 1.9-14.8; North West, aHR: 4.8, 95\% CI: 1.8-12.6; Western Cape, aHR: 4.1, 95\% CI: 1.4-11.7; Eastern Cape: aHR: 3.2, 95\% CI: 1.1-9.3) (Table 3).

Infants whose mothers had not heard of PMTCT prior to the six week interview had higher hazard of nonadherence within the 6 week to 18 month postpartum period than those whose mothers had heard of PMTCT (aHR: 1.6, 95\% CI: 0.9-32.8; $p$ value $<0.10$ ), although this was not significant at $5 \%$. Not knowing the mother's partner's HIV status showed increased hazard for nonadherence (aHR: 1.4, 95\% CI: 10.9-2.1; $p$ value $<0.10$ ) but this was not significantly at $5 \%$. Maternal parity was included in the model but was not significantly associated with adherence.

\section{Discussion}

Adherence to antiretroviral treatment among mothers and infants until 18 months postpartum

This study observed suboptimal ART adherence until 18 months postpartum among this cohort of HIV-positive mothers and infants, with below $65 \%$ of mothers and below $75 \%$ of infants cumulatively maintaining adherence over $95 \%$ from 6 weeks to 18 months postpartum. This is gravely concerning, given the global policy shift to lifelong ART amongst pregnant and lactating women, and the need for extended infant prophylaxis amongst mothers who are not virally suppressed. We found ART adherence to be higher at earlier time points, with both mothers and infants over $85 \%$ adherent by 14 weeks over or about $80 \%$ by 6 months. A similar analysis of infant ART adherence in Zambia showed a lower adherence until 6 months of about 70\% (versus our result of 93.0\%), and until 18 months of just above 0\% (versus our result of 73.4\%) [36]. A study from Malawi showed lower maternal ART adherence than our study, with $75 \%$ adherence by 3 months, about $50 \%$ adherence by 6 months, and under $40 \%$ adherence by 18 months [37]. While the study in Malawi used a pharmacy-based adherence measure, our study utilized self-reported adherence which tends to overestimate adherence due to recall bias and social desirability. This may account for the differences in adherence seen across these two studies. Results from a systematic review of adherence among women on ART in low- middle- and high-income countries reported adherence of 53\% (95\% CI: 33-73) during the postnatal period, although the timeframe was not specifically defined [4]. While our results from this cohort of mothers and infants indicate higher ART adherence than that seen in similar studies from the region, possibly because of the Hawthorne effect [38] as a result of threemonthly follow-up by nurses, adherence reported herein 
Table 2 Frequency of nonadherence types per interval and cumulative probability of adherence to ART among a cohort of mothers $(N=1572)$ and NVP among a cohort of infants $(N=2370)$ from 6 weeks to 18 months postpartum in South Africa followed in 20122014 (unweighted)

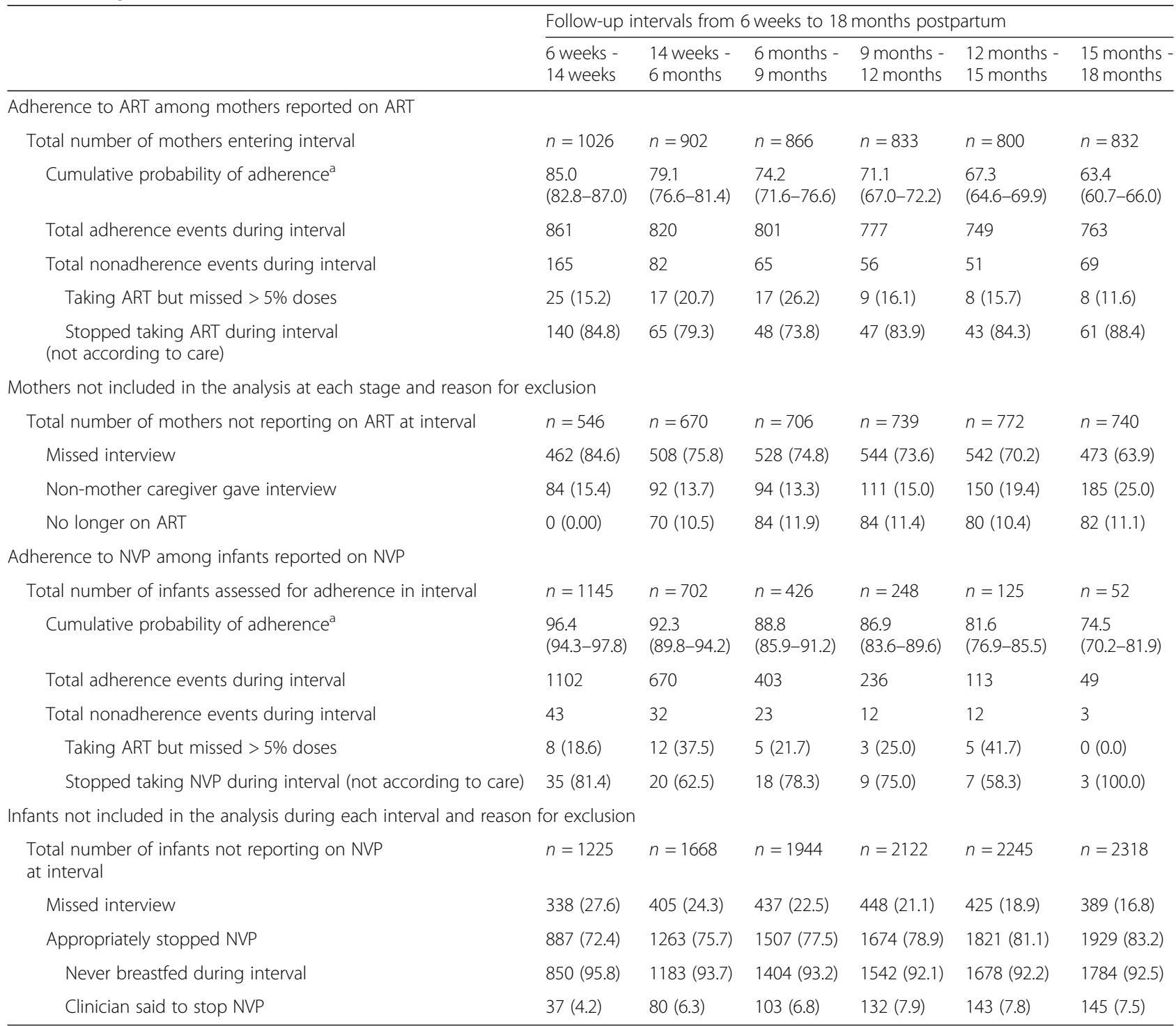

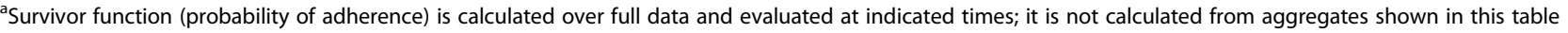

remains suboptimal to eliminate MTCT and highlights room for improvement on the implementation of PMTCT guidelines [5, 24].

Infant adherence was higher than mother adherence by about $10 \%$ across the entire 6 weeks to 18 months postpartum period. This may suggest that efforts made by the mother to ensure adherence within the motherinfant pair are prioritized toward the infant's HIV prophylaxis adherence over her own HIV treatment.

\section{Risk factors of nonadherence to ART among mothers}

We identified risk factors for nonadherence to inform further improvements to PMTCT programming. Adolescents and young women in this cohort (age 16-24 years) had a higher hazard of nonadherence than women older than 25, consistent with similar studies about PMTCT and maternal and child health seeking [39-41]. A study from Uganda indicates that this is potentially due to lack of knowledge and experience with childbirth and health, as well as age-related discrimination from the heath system [42]. In South Africa, adolescent girls and young women have particularly high risk for acquiring HIV infection and low uptake of HIV services [43]. Targeted HIV interventions to increase HIV prevention and service coverage among this high risk group were initiated in South Africa in 2015.

Initiating ART after delivery was a risk factor for nonadherence among mothers, indicating that initiation on 
Table 3 Unadjusted and adjusted risk factors for nonadherence to ART among a cohort of mothers and NVP among a cohort of infants in South Africa followed in 2012-2014 identified with cox proportional hazards model (unweighted)

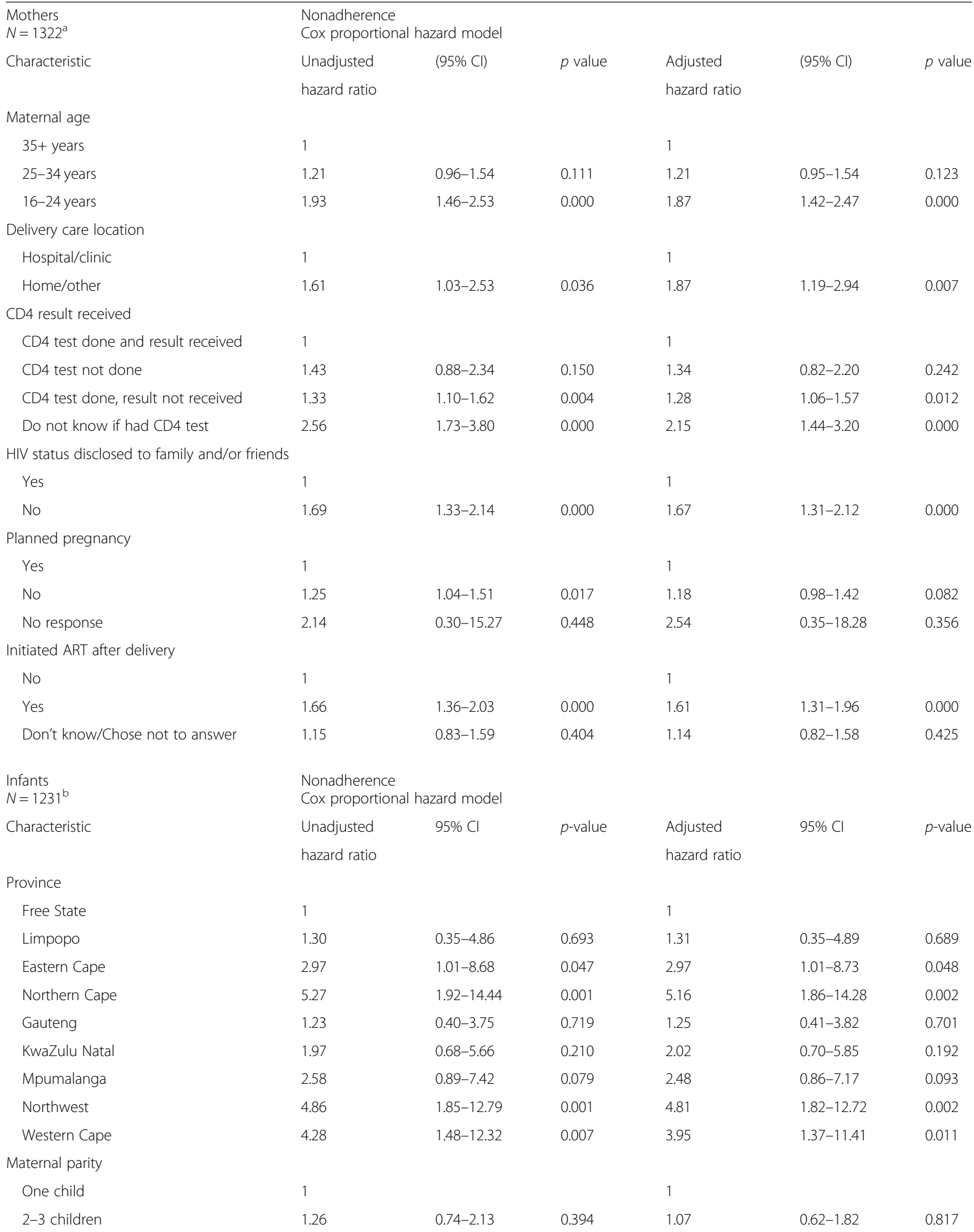


Table 3 Unadjusted and adjusted risk factors for nonadherence to ART among a cohort of mothers and NVP among a cohort of infants in South Africa followed in 2012-2014 identified with cox proportional hazards model (unweighted) (Continued)

\begin{tabular}{|c|c|c|c|c|c|c|}
\hline $4+$ children & 1.68 & $0.90-3.16$ & 0.106 & 1.45 & $0.76-2.75$ & 0.259 \\
\hline \multicolumn{7}{|c|}{ Mother ever heard of PMTCT } \\
\hline Yes & 1 & & & 1 & & \\
\hline No & 1.76 & $1.01-3.06$ & 0.044 & 1.70 & $0.96-3.00$ & 0.068 \\
\hline \multicolumn{7}{|c|}{ Mother knows partner's HIV status } \\
\hline Yes & 1 & & & 1 & & \\
\hline No & 1.48 & $0.98-2.24$ & 0.061 & 1.46 & $0.97-2.21$ & 0.072 \\
\hline
\end{tabular}

${ }^{a}$ Mothers were included in survival analysis if they were on ART at 6 weeks and had information about ART adherence at any follow-up visit

bInfants were included in survival analysis if they were on NVP at birth and had information about NVP adherence at any follow-up visit

ART earlier in the continuum of care may be an important protective measure to improve adherence. The current national guidelines entitling all HIV positive pregnant and breastfeeding women to lifelong ART partially address this concern [5]. Additionally, messaging that encourages timely attendance to antenatal care visits among pregnant women in South Africa may increase early initiation on ART [44].

Knowledge of one's CD4 count protected mothers from nonadherence, indicating that compliance with CD4 testing and returning of test results to patients may have contributed to improved adherence to ART among mothers. At the time of these data, ART initiation was based on CD4 count $<350$ under Option B guidelines, therefore for mothers who were not experiencing symptoms and therefore did not feel the pressing need for ART adherence, CD4 results may have offered a motivating factor $[45,46]$. Counseling messages from health providers received with CD4 test results could have improved a mother's understanding of the importance of ART adherence to PMTCT, thus reducing nonadherence [47]. This confusion around CD4 count is no longer an anticipated barrier at the present era of test and treat for life.

Disclosure of HIV status to family and friends was protective from nonadherence within this cohort, as seen in other studies from South Africa and other subSaharan African settings [48-50]. These studies postulated that the psychosocial support gained through disclosure, as well as the accountability to one's treatment, encourage adherence. PMTCT programmatic messages should encourage mothers to disclose their HIV status to improve ART adherence. Furthering the case for support as a protective factor against nonadherence is the result that married and cohabitating mothers showed lower nonadherence than single, divorced, and widowed women.

Mothers who delivered their infants in health facilities had lower hazard of nonadherence than those who delivered outside of a formal health facility. We postulate that this is due to additional support provided when a delivery is in a health facility. Other studies have found that individuals exhibiting high health seeking behavior have been found to have higher adherence to ART [51]. Messages about the importance of ART adherence for PMTCT are provided whenever a mother interacts with the health system along the continuum of care [12], thus those delivering in a facility receive a higher frequency of these messages.

\section{Adjusted risk factors of nonadherence to Nevirapine among infants}

Provincial variation in nonadherence may be indicative of inconsistencies in effectiveness of PMTCT, potentially explained by a complex network of differences in relative strength of the provincial health systems, messaging surrounding the importance of PMTCT, the general status of health, and geography. As a highly dynamic and migratory population, variation in health seeking behavior is expected, as noted in other studies [17, 43, 52].

\section{Limitations}

By nature of the population followed until 18 months postpartum by the national PMTCT Evaluation study, the present study did not include adherence for HIV-exposed infants who had a positive PCR result at 6 weeks or their mothers. As a cohort analysis observing a subgroup from this follow-up population, the results were not adjusted for the study design, non-response and not weighted for live-births, thus limiting the representativeness of these results.

The Andersen-Gill extended cox proportional hazards model selected for this analysis requires a strong statistical assumption of independence across the increments in which nonadherence events can occur [35]. This assumes that a nonadherence event is not influenced by a prior nonadherence event within a study participant. Thus, event dependence is not included in the model. Without strong evidence to support dependence across nonadhernece events, we chose this model. 
ART adherence was evaluated on self-reported responses, therefore issues of false reporting and recall likely biased the results, however we cannot determine whether these are under- or over-estimates. To minimize such information bias we checked road-tohealth cards to verify maternal self-report of HIV status and ART uptake. The consistency between maternal selfreport of these measures and the record from the road-tohealth card increased our confidence in other self-reported measures.

A high proportion of mothers and infants included in the follow-up study missed interviews during the 18 month follow-up period. Due to the lack of information about these participants at intervals where the interview was missed, participants were not included in the analysis for any missed interval, likely introducing bias into the results. There was no date of failure captured for mothers who stopped taking ART during an interval, thus the midpoint was used which could have under- or over-estimated the time contributed.

A higher probability of adherence during later analysis time may been driven by loss to follow-up of non-adherent women and may not reflect an actual improvement in adherence, as women with poor adherence are at higher risk of loss to follow-up than those with good adherence $[37,53]$. This mechanism of "informative censoring" biases analysis of adherence patterns over time.

The population studied herein is highly dynamic [17, $54,55]$, exemplified by the fact that individuals could move in and out of the included study population at each follow-up interval. Such mobility likely contributes to the low adherence seen here, both by providing a barrier to adherence among mothers and their infants and by posing a challenge to measurement within our follow-up interviews. The high proportion of missed interviews underscores the importance of strengthening counseling to ensure that individuals understand the importance of ART adherence to viral suppression, reducing risk of MTCT, and reducing risk of drug resistance. Mothers were continually counseled on the importance of adherence to health outcomes throughout the course of the study, especially when non-adherence events were identified.

\section{Conclusion}

Our findings from this cohort of mothers and infants in South Africa suggest that suboptimal adherence to ART for PMTCT persists, which likely contributes to remaining mother-to-child HIV transmission events. Results from this cohort of mothers and infants in South Africa suggest that young mothers are an important target for the PMTCT national program with messages stressing the importance of adherence; all pregnant women and mothers need support to disclose their HIV status to loved ones, to deliver in a facility, and to know their CD4 count to improve ART adherence. Additionally, a mother's knowledge of PMTCT and knowledge of her partner's HIV status could improve infant adherence to Nevirapine.

\section{Abbreviations}

aHR: adjusted Hazard Ratio; ANC: Antenatal care; ART: Antiretroviral therapy; EMTCT: Elimination of mother-to-child transmission of HIV; HIV: Human immunodeficiency virus; MTCT: Mother-to-child transmission of HIV; NVP: Nevirapine; PLHIV: People living with HIV; PMTCTm: Prevention of mother-to-child transmission of HIV; WHO: World Health Organisation

\section{Acknowledgements}

The authors thank all the women and children who participated in this study, all data collectors and supervisors, all provincial maternal and child health/PMTCT managers, all laboratory staff and members of the South Africa PMTCT Evaluation team. The research was performed by the South African Medical Research Council (MRC) through a grant from the President's Emergency Plan for AIDS Relief (PEPFAR) through the Centers for Disease Control and Prevention, under the terms of Cooperative Agreement Number 5U2GPS001137-4. The South African Medical Research Council (SAMRC) funded the publication of this paper. The findings and conclusions in this paper are those of the authors and do not necessarily represent the official position of the funding agencies.

\section{About this supplement}

This article has been published as part of BMC Infectious Diseases Volume 19 Supplement 1, 2019: Evaluating the effectiveness of national programmes to prevent vertical HIV transmission: Methods, results and implications for PMTCT Option B+ from South Africa. The full contents of the supplement are available online at https://bmcinfectdis.biomedcentral.com/articles/ supplements/volume-19-supplement-1.

\section{Authors' contributions}

$A L, V M$, and $A G$ conceptualized the manuscript. VM, NN, and WC managed data collection. AL performed data analysis and TD, CL, KA, and $A G$ advised data analysis and interpretation. $A L$ drafted the manuscript with significant input from $A G$, and $M C$. AL, VM, TD, NN, CL, MC, KA, WC, GK, DJ, and AG performed critical revision of the article. All authors read and approved the final manuscript.

\section{Funding}

The research was funded through a grant from the President's Emergency Plan for AIDS Relief (PEPFAR) through the Centers for Disease Control and Prevention, under the terms of Cooperative Agreement Number 5U2GPS001137-4. The South African Medical Research Council (SAMRC) funded the publication of this paper.

\section{Availability of data and materials}

Not applicable.

Ethics approval and consent to participate

No ethical approval was needed for this work.

\section{Consent for publication}

Not applicable.

\section{Competing interests}

The authors declare that they have no competing interests.

\section{Author details}

${ }^{1}$ Division of Global HIV/AIDS and Tuberculosis, Center for Global Health, US Centers for Disease Control and Prevention (CDC), Pretoria, South Africa. ${ }^{2}$ Health Systems Research Unit, South African Medical Research Council (HSRU, SAMRC), Pretoria, South Africa. ${ }^{3}$ Division of Global HIV/AIDS and Tuberculosis, Center for Global Health, US Centers for Disease Control and Prevention (CDC), Atlanta, GA, USA. ${ }^{4}$ United Nations Children's Fund (UNICEF), New York, NY, USA. ${ }^{5}$ School of Public Health, University of the 
Western Cape, Cape Town, South Africa. ${ }^{6}$ Department of Paediatrics, University of Pretoria, Pretoria, South Africa. ${ }^{7}$ HIV Prevention Research Unit, South African Medical Research Council, 123 Jan Hofmeyr Road, Westville, Durban, KwaZulu-Natal 3630, South Africa.

Published: 16 September 2019

\section{References}

1. UNAIDS. Countdown to zero - global plan towards the elimination of new HIV infections among children by 2015 and keeping their mothers alive. 2011. Available from: http://files.unaids.org/en/media/unaids/contentassets/ documents/unaidspublication/2011/20110609_JC2137_Global-PlanElimination-HIV-Children_en.pdf

2. UNAIDS. Prevention gap report. 2016. Available from: http://www.unaids. org/sites/default/files/media_asset/2016-prevention-gap-report_en.pdf.

3. Siegfried N, van der Merwe L, Brocklehurst P, Sint TT. Antiretrovirals for reducing the risk of mother-to-child transmission of HIV infection. Cochrane Database Syst Rev. 2011:CD003510 [cited 2016 Oct 11]. Available from: http://www.ncbi.nlm.nih.gov/pubmed/21735394.

4. Nachega JB, $\mathrm{O}$ a U, Anderson J, Peltzer $\mathrm{K}$, Wampold $\mathrm{S}$, Cotton MF, et al. Adherence to antiretroviral therapy during and after pregnancy in lowincome, middle-income, and high-income countries. Aids. 2012;26:2039-52.

5. World Health Organization. Elimination of mother-to-child transmission (EMTCT) of HIV and syphilis. Geneva: World Health Organization; 2014. Available from: http://www.who.int/reproductivehealth/publications/rtis/ 9789241505888/en/

6. Tsague L, Abrams EJ. Antiretroviral treatment for pregnant and breastfeeding women - the shifting paradigm. AIDS. 2014;28:S119-S121. World Health Organization; [cited 2016 Oct 11]. Available from: http://www. who.int/hiv/pub/journal_articles/art_pregnant-and-brestfeeding-women/en/.

7. UNAIDS. AIDS by the numbers 2016. 2016. Available from: http://www. unaids.org/en/resources/documents/2016/AIDS-by-the-numbers.

8. HSRC. South African National HIV Prevalence, Incidence and behaviour survey, 2012. 2014 [cited 2016 Feb 9]. Available from: http://www.hsrc.ac.za/ uploads/pageContent/4565/SABSSM IV LEO final.pdf.

9. UNAIDS. The gap report. Geneva: HSRC; 2014. Available from: http://www. unaids.org/sites/default/files/media_asset/UNAIDS_Gap_report_en.pdf

10. Health Systems Trust. The 2013 National Antenatal Sentinel HIV Prevalence Survey South Africa. Pretoria: UNAIDS; 2014. Available from: http://www.kznhealth. gov:za/data/The-2013-National-Antental-Sentinel-HIV-Prevalence-Survey-SouthAfrica.pdf.

11. Goga AE, Dinh T-H, Jackson DJ, Lombard C, Delaney KP, Puren A, et al. First population-level effectiveness evaluation of a national programme to prevent HIV transmission from mother to child, South Africa. J Epidemiol Community Health. 2015;69:240-8 Available from: http://www. pubmedcentral.nih.gov/articlerender.fcgi?artid=4345523\&tool= pmcentrez\&rendertype $=$ abstract.

12. National Department of Health of South Africa. The South African Antiretroviral Treatment Guidelines. 2010; Available from: http://apps.who. int/medicinedocs/documents/s19153en/s19153en.pdf

13. Goga AE, Dinh T-H, Jackson DJ, Lombard C, Puren A, Sherman G, et al. Population-level effectiveness of PMTCT option a on early mother-to-child (MTCT) transmission of HIV in South Africa: implications for eliminating MTCT. J Glob Health. 2016;6:020405Available from: https://www.ncbi.nlm.nih. gov/pubmed/27698999.

14. World Health Organization. Use of antiretroviral drugs for treating pregnant women and preventing HIV infection in infants. Geneva: World Health Organization; 2012. Available from: http:/www.who.int/hiv/pub/mtct/ programmatic_update2012/en/

15. Bhardwaj S. South Africa announces change in PMTCT regimen from April 1, 2013. Pretoria: UNICEF; 2012. Available from: http://emtct-iatt.org/2 012/12/south-africa-announces-change-in-pmtct-regimen-from-april-1-2013/

16. UNICEF. Option B+ countries and PMTCT regimen. IATT website. 2015. Available from: http://emtct-iatt.org/b-countries-and-pmtct-regimen/

17. Massyn N, Peer N, Padarath A, Barron P, Day C. District Health Barometer. Statew. Agric. L. Use Baseline 2015. Pretoria: Health Systems Trust; 2015.

18. Nachega J, VC M, van Zyl G, Gardner E, Preiser W, Hong S, et al. HIV treatment adherence, drug resistance, Virologic failure: evolving concepts. Infect Disord Drug Targets. 2011;11:167-174. cited 2016 Oct 13]. Available from: http://www.eurekaselect.com/87802/article.
19. Stirratt MJ, Dunbar-Jacob J, Crane HM, Simoni JM, Czajkowski S, Hilliard $M E$, et al. Self-report measures of medication adherence behavior: recommendations on optimal use. Transl Behav Med. 2015;5:470-82 [cited 2018 Apr 28]. Available from: http://www.ncbi.nlm.nih.gov/ pubmed/26622919.

20. Simoni JM, Kurth AE, Pearson CR, Merrill JO, P A F. Self-report measures of antiretroviral therapy adherence: A review with recommendations for HIV research and clinical management. AIDS Behav. 2014;10:227-45.

21. Nieuwkerk PT, Oort FJ. Self-reported adherence to antiretroviral Therapy for HIV-1 infection and virologic treatment response. J Acquir Immune Defic Syndr. 2005;38:445-8 [cited 2016 Oct 13]. Available from: https://www. researchgate.net/publication/7969555_Self-Reported_Adherence_to_ Antiretroviral_Therapy_for_HIV-1_Infection_and_Virologic_Treatment_ Response_A_Meta-analysis.

22. Berg KM, Wilson IB, Li X, Arnsten JH. Comparison of antiretroviral adherence questions. AIDS Behav. 2012;16:461-8.

23. Mannheimer S, Friedland G, Matts J, Child C, Chesney M. The consistency of adherence to antiretroviral therapy predicts biologic outcomes for human immunodeficiency virus-infected persons in clinical trials. Clin Infect Dis. 2002;34:1115-21 [cited 2016 Oct 13]. Available from: https://www. researchgate.net/publication/11449539_The_Consistency_of_Adherence_ to_Antiretroviral_Therapy_Predicts_Biologic_Outcomes_for_Human_ Immunodeficiency_Virus-Infected_Persons_in_Clinical_Trials.

24. Paterson DL, Swindells S, Mohr J, Brester M, Vergis EN, Squier C, et al. Adherence to anti-HIV therapy and the outcome of treatment. Ann Intern Med. 2000;133:21 [cited 2016 Oct 13]. Available from: https://www. researchgate.net/publication/12440711_Adherence_to_Protease_Inhibitor_ Therapy_and_Outcomes_in_Patients_with_HIV_Infection.

25. Fadnes LT, Jackson D, Engebretsen IMS, Zembe W, Sanders D, Sommerfelt $H$, et al. Vaccination coverage and timeliness in three South African areas: a prospective study. BMC Public Health. 2011;11:404 [cited 2016 Feb 5]. Available from: https://www.researchgate.net/publication/51171954 Vaccination_coverage_and_timeliness_in_three_South_African_areas_a_ prospective_study_BMC_Public_Health_11404.

26. Stata User's manual 13: stcurve syntax [internet]. College Station: Stata Corp; 2013. Available from: https://www.stata.com/manuals13/ststcurve.pdf. Accessed 13 Oct 2016.

27. Stata User's manual 13: stcox syntax [internet]. College Station: Stata Corp; 2013. Available from: https://www.stata.com/manuals13/ststcox.pdf. Accessed 13 Oct 2016

28. Amorim LD, Cai J. Modelling recurrent events: a tutorial for analysis in epidemiology. Int J Epidemiol. 2015;44:324-33 Oxford University Press; [cited 2017 Dec 19]. Available from: https://academic.oup.com/ije/articlelookup/doi/10.1093/ije/dyu222.

29. Cleves M. Analysis of multiple failure-time survival data. Stata Tech Bull. 1999; [cited 2017 Dec 19]. Available from: https:/www.stata.com/support/ faqs/statistics/multiple-failure-time-data/.

30. Hosmer DW Jr, Lemeshow S, May S. Applied survival analysis: regression modeling of time to event data. Hoboken: Wiley; 2011. [cited 2016 Oct 13]. Available from: https://books.google.com/books?id=EB3g9YG6p6IC\&pgis=1

31. Andersen PK, Gill RD. Cox 's regression model for counting processes : a large sample study. Ann Stat. 1982;10:1100-20.

32. Kelly PJ, LL-Y L. Survival analysis for recurrent event data: an application to childhood infectious diseases. Stat Med. 2000;19:13-33 John Wiley \& Sons, Ltd.; [cited 2017 Dec 19]. Available from: http://doi.wiley.com/10.1002/\%2 8SICI\%291097-0258\%2820000115\%2919\%3A1\%3C13\%3A\%3AAID-SIM279\%3 E3.0.CO\%3B2-5.

33. Kennedy BS, Kasl SV, Vaccarino V. Repeated Hospitalizations and Self-rated Health among the Elderly: A Multivariate Failure Time Analysis. Am. J. Epidemiol. 2001;153:232-41 Oxford University Press; [cited 2017 Dec 19]; Available from: https://academic.oup.com/aje/article-lookup/doi/10.1093/ aje/153.3.232.

34. Pandeya N, Purdie DM, Green A, Williams G. Repeated Occurrence of Basal Cell Carcinoma of the Skin and Multifailure Survival Analysis: Follow-up Data from the Nambour Skin Cancer Prevention Trial. Am J Epidemiol. 2005;161: 748-54 Oxford University Press; [cited 2017 Dec 19]. Available from: https:// academic.oup.com/aje/article-lookup/doi/10.1093/aje/kwi098.

35. Ullah S, Gabbett TJ, Finch CF. Statistical modelling for recurrent events: an application to sports injuries. Br J Sports Med. 2014;48:1287-93 BMJ Publishing Group Ltd and British Association of Sport and Exercise Medicine [cited 2017 Dec 19]. Available from: http://www.ncbi.nlm.nih.gov/pubmed/22872683. 
36. Okawa S, Chirwa M, Ishikawa N, Kapyata H, Msiska CY, Syakantu G, et al. Longitudinal adherence to antiretroviral drugs for preventing mother-tochild transmission of HIV in Zambia. BMC Pregnancy Childbirth. 2015;15:258 [cited 2016 Oct 17]. Available from: https://www.researchgate.net/ publication/283768742_Longitudinal_adherence_to_antiretroviral_drugs_ for_preventing mother-to-child transmission_of HIV in Zambia.

37. Haas AD, Msukwa MT, Egger M, Tenthani L, Tweya $H$, Jahn A, et al. Adherence to antiretroviral therapy during and after pregnancy: cohort study on women receiving Care in Malawi's option B+ program. Clin Infect Dis. 2016;63:ciw500 Available from: http://cid.oxfordjournals.org/lookup/ doi/10.1093/cid/ciw500.

38. McCambridge J, Witton J, Elbourne DR. Systematic review of the Hawthorne effect: new concepts are needed to study research participation effects. J Clin Epidemiol. 2014;67:267-77 [cited 2018 Mar 8]. Elsevier. Available from: http://www.ncbi.nlm.nih.gov/pubmed/24275499.

39. Kirsten I, Sewangi J, Kunz A, Dugange F, Ziske J, Jordan-Harder B, et al. Adherence to combination prophylaxis for prevention of mother-to-childtransmission of HIV in Tanzania. PLoS One. 2011;6:e21020 [cited 2016 Oct 17]. Public Library of Science. Available from: http://journals.plos.org/ plosone/article?id=10.1371/journal.pone.0021020.

40. Stringer EM, Creek TL, Stinson K, Giganti MJ, Welty TK, Chi BH, et al. Coverage of nevirapine-based services to prevent mother-to-Child HIV transmission in 4 African countries, vol. 304; 2016. p. 293-302.

41. Taffa N, Chepngeno G. Determinants of health care seeking for childhood illnesses in Nairobi slums. Trop Med Int Health. 2005;10:240-5. https://doi. org/10.1111/j.1365-3156.2004.01381.x African Population and Health Research Center, Nairobi, Kenya negu1@botusaorg SRC - Pubmed ID2 15730508 FG - 0.

42. Atuyambe L, Mirembe F, Tumwesigye NM, Annika J, Kirumira EK, Faxelid E. Adolescent and adult first time mothers' health seeking practices during pregnancy and early motherhood in Wakiso district, central Uganda. Reprod Health. 2008;5:13 BioMed Central; [cited 2016 Oct 20]. Available from: http:// reproductive-health-journal.biomedcentral.com/articles/10.1186/1742-4755-5-13.

43. Dellar RC, Dlamini S, Karim QA. Adolescent girls and young women: key populations for HIV epidemic control. J Int AIDS Soc. 2015;18:64-70.

44. Myer L, Zulliger R, Bekker L-G, Abrams E. Systemic delays in the initiation of antiretroviral therapy during pregnancy do not improve outcomes of HIVpositive mothers: a cohort study. BMC Pregnancy Childbirth. 2012;12:94 [cited 2016 Aug 9]. BioMed Central; Available from: http://bmcpregnancychildbirth. biomedcentral.com/articles/10.1186/1471-2393-12-94.

45. Duff P, Kipp W, Wild TC, Rubaale T, Okech-Ojony J. Barriers to accessing highly active antiretroviral therapy by HIV-positive women attending an antenatal clinic in a regional hospital in western Uganda. J Int AIDS Soc. 2010;13:37 BioMed Central; [cited 2016 Oct 17]. Available from: http:// jiasociety.biomedcentral.com/articles/10.1186/1758-2652-13-37.

46. Levy JM. Women's expectations of treatment and care after an antenatal HIV diagnosis in Lilongwe, Malawi. Reprod. Health Matters. 2009;17:152-61 [cited 2016 Oct 17]. Available from: https://www.researchgate.net/ publication/26289394_Women's_expectations_of_treatment_and_care_ after_an_antenatal_HIV_diagnosis_in_Lilongwe_Malawi.

47. ICAP. Psychosocial support within PMTCT services a toolkit for health workers introduction to the toolkit. 2014.

48. Mills EJ, Nachega JB, Bangsberg DR, Singh S, Rachlis B, Wu P, et al. Adherence to HAART: a systematic review of developed and developing nation patient-reported barriers and facilitators. PLoS Med. 2006;3:e438 Public Library of Science; [cited 2016 Oct 17]; Available from: http://journals. plos.org/plosmedicine/article?id=10.1371/journal.pmed.0030438.

49. Ware NC, Idoko J, Kaaya S, Biraro IA, Wyatt MA, Agbaji O, et al. Explaining adherence success in sub-Saharan Africa: an ethnographic study. PLoS Med. 2009;6:e11 Public Library of Science; [cited 2016 Oct 17]; Available from: http:// journals.plos.org/plosmedicine/article?id=10.1371/journal.pmed.1000011.

50. Peltzer K, Mosala T, Dana P, Fomundam H. Follow-up survey of women who have undergone a prevention of mother-to-child transmission program in a resource-poor setting in South Africa. J Assoc Nurses AIDS Care. 2008;19: 450-60 [cited 2016 Oct 17]. Available from: http://www.sciencedirect.com/ science/article/pii/S1055329008001842.

51. Gourlay A, Birdthistle I, Mburu G, lorpenda K, Wringe A. Barriers and facilitating factors to the uptake of antiretroviral drugs for prevention of mother-to-child transmission of HIV in sub-Saharan Africa: a systematic review. J Int AIDS Soc. 2013 \:18588. [cited 2016 Oct 17]; Available from: http://www.jiasociety.org/index.php/jias/article/view/18588/3121
52. Peltzer K, Mlambo M, Phaswana-Mafuya N, Ladzani R. Determinants of adherence to a single-dose nevirapine regimen for the prevention of mother-to-child HIV transmission in Gert Sibande district in South Africa. Acta Paediatr Int J Paediatr. 2010;99:699-704.

53. Haas AD, Tenthani L, Msukwa MT, Tal K, Jahn A, Gadabu OJ, et al. Retention in care during the first 3 years of antiretroviral therapy for women in Malawi's option B+ programme: an observational cohort study. Lancet HIV. 2016;3:e175-82 Elsevier; [cited 2017 Sep 27]; Available from: http:// linkinghub.elsevier.com/retrieve/pii/S2352301816000084.

54. Landau LB. Gauteng 2055 trend paper: population \& migration. 2008; Available from: http://migration.org.za

55. South African Census Bureau. Statistical release ( Revised) Census 2011, vol. 78; 2012. Available from: www.statssa.gov.za

\section{Publisher's Note}

Springer Nature remains neutral with regard to jurisdictional claims in published maps and institutional affiliations.

\section{Ready to submit your research? Choose BMC and benefit from:}

- fast, convenient online submission

- thorough peer review by experienced researchers in your field

- rapid publication on acceptance

- support for research data, including large and complex data types

- gold Open Access which fosters wider collaboration and increased citations

- maximum visibility for your research: over $100 \mathrm{M}$ website views per year

At BMC, research is always in progress.

Learn more biomedcentral.com/submissions 